\title{
28 Research Square \\ Evaluation of the Potential Effect of Cry1Ab Expressing Straw on ICR Mice
}

Bo Lv

Hunan Normal University

Yun-e Tang

Hunan Normal University

Chao-min Li

Hunan Agriculture University

Ou-lin Dai

Hunan Agriculture University

Yong Peng

Hunan Normal University

Li-jun Chen

Shaoyang University

Zhi Wang ( $\square$ wangzhispider@hotmail.com )

Hunan Normal University

\section{Research Article}

Keywords: Cry1Ab protein, Genetically modified crops, Apoptosis, Antioxidase, Risk assessment

Posted Date: November 16th, 2021

DOI: https://doi.org/10.21203/rs.3.rs-1027730/v1

License: (1) (1) This work is licensed under a Creative Commons Attribution 4.0 International License.

Read Full License 


\section{Abstract}

Cry $1 \mathrm{Ab}$ toxin has been effectively integrated into crops such as rice and cotton for pest control, and the safety evaluation of transgenic rice has attracted widespread attention. Nevertheless, the effects of transgenic rice straw on animal model are still unclear. Hence, the present study conducted an integrated analysis to evaluate the unintended effects of transgenic rice straw expressing Cry $1 \mathrm{Ab}$ protein on the Institute of Cancer Research (ICR) mice under 90-day treatment. The results indicated that Cry1 Ab rice straw had no significant effects on the behavior and body weight of mice. In addition, physiological indicators, including hemogram, blood biochemistry, apoptosis rate, and calcium ion concentration of the blood lymphocytes, displayed no alterations under Cry1Ab protein stress. Similarly, Cry1Ab rice straw had no adverse effects on several antioxidase activities (i.e., catalase, superoxide dismutase, peroxidase, glutathione peroxidase, and acetylcholine esterase). Moreover, we recorded that Cry1 Ab stress did not adversely impact the sperm quality and follicular development of male and female ICR mice. Collectively, this integrated analysis indicates that Cry $1 \mathrm{Ab}$ rice straw has no adverse or toxic effects on ICR mice after 90-day treatment and provides multi-level perspectives to assess the safety of genetically modified crops on non-target mammals.

\section{Introduction}

Rice (Oryza sativa L.) is the most important food crop in China, and more than half of the world's population relying on rice as the primary food intake (Li et al., 2018; Liu et al., 2020). Therefore, increasing rice yield and improving rice quality has become a crucial strategic target of sustainable development. Nonetheless, pests such as Sesamia inferens, Tryporyza incertulas, and Nilaparvata lugens have become disastrous factors restricting rice yield (Liu et al., 2011; Ye et al., 2009; Zheng et al., 2021). There are nearly 400 species of rice pests in China, including Lepidoptera and Coleoptera, posing life-threatening challenges to rice. Meanwhile, growing studies have demonstrated that pests in paddy fields have lost up to 10 billion kilograms of total global rice production (Savary et al., 2019). Hence, preventing and solving the adverse effects of rice pests on economic crops (e.g., rice, cotton and corn) has become a hot issue in the current social development.

Bacillus thuringiensis $(B t)$ is a gram-positive bacterium that can secrete multiple parasporal crystals (Melo et al., 2016). The parasporal crystals have specific insecticidal activity against Coleoptera, Homoptera, Lepidoptera and other specific insects (Bel et al., 2020; Melo et al., 2016). Hitherto, more than 100 insecticidal crystal proteins have been isolated, and the Cry $1 \mathrm{Ab} / \mathrm{Ac}$ protein is recognized as one of the most widely used $B t$ protein. With the gradual maturity of transgenic technology, transgenic $B t$ crops, including cotton, corn, and rice, have been primarily utilized in different areas (Li et al., 2019; Riaz Marral et al., 2020; Song et al., 2020). Nonetheless, the promotion of genetically modified crops (GMCs) is restricted to some extent. Some organizations believe that GMCs, as "new species", occupy the new environment and may also cause genetic environment pollution or adverse effects on human health. 
Previous studies have indicated that broilers fed VIP3A transgenic maize and $B t$ transgenic maize have no significant difference in performance compared with the control (Raybould and Vlachos, 2011). Similarly, there were no significant alterations in growth and development indexes of pigs fed with $B t$ maize (Liu et al., 2018). In addition, many scholars have carried out a large number of studies on the drug and toxicology of transgenic Bt rice on rats (Wang et al., 2014; Wang et al., 2013a). Feeding Bt protein powder caused intestinal disorder in mice, which was manifested by changes in the number of bifidobacteria (Schrøder et al., 2007). However, growing studies have shown that under long-term and chronic Bt stress, the body weight, feed intake, and organ index of mice fed with transgenic rice have little difference compared with that of the control, and various indexes of blood (blood phase, blood biochemistry, etc.) were unchanged, and organ biopsy results showed no disease and toxic effects (Hajimohammadi et al., 2021; Song et al., 2015; Wang et al., 2013b). In addition, neither germ cells nor somatic cells had mutagenic activity or presented a dose-independent effect (Carrière et al., 2009; Xing et al., 2019).

Compared with non-transgenic rice, there were no significant differences in organ indexes, physiological behavior, blood indexes, and immune capacity of experimental animals under $B t$ stress. Nevertheless, rice is one of the dominant food crops in China, and rice straw is an important feed source for cattle (especially in southern China) to survive the winter. Therefore, it is still of great significance to evaluate GMCs' biological impact on organisms' derivatives. In this study, Institute of Cancer Research (ICR) mice were fed with Bt rice straw powder for 90 days, then the growth indexes, physiological indicators and antioxidants of mice were detected, and it was found that $B t$ rice straw powder did not have adverse effects on mice.

\section{Materials And Methods}

\section{Ethics statement}

This study was approved by Hunan Normal University ethics committee. All experiments were carried out in compliance with the ARRIVE guidelines. All methods were carried out in accordance with relevant guidelines and regulations.

\section{Rice straw sample preparation}

The rice straw of the transgenic Shanyou 63 rice expressing Cry $1 \mathrm{Ab}$ protein and its non-transgenic parental wild type Shanyou 63 rice were obtained from the Life Science College, Hunan Science and Technology University. The rice straw was kept in a ventilated, clean, and dry place under $23 \pm 2{ }^{\circ} \mathrm{C}$.

\section{Feed}

Control (non-Bt rice straw) feed: B-grade mice feed was purchased from Hunan Slack Scene of Laboratory Animal Co., LTD. The ordinary feed contains the following main nutrients: protein $>20 \%$, crude fat $>4 \%$, crude fiber $<5 \%$, crude ash $<8 \%$, moisture $<10 \%$, calcium $1.0-1.8 \%$, phosphorus $0.6-1.2 \%$. The 
control feed was prepared by uniformly mixing the non-Bt rice straw powder (ultrafine grinding) with the ordinary feed at the ratio of $1: 3$. Feed was kept in a ventilated, clean, and dry place under $23 \pm 2{ }^{\circ} \mathrm{C}$.

$B t$ rice straw feed: For the feeding test group of mice, the ordinary feed was uniformly mixed with $B t$ rice straw powder (ultrafine grinding) and ordinary feed ingredient at the ratio of 1:3. Feed was kept in a ventilated, clean, and dry place under $23 \pm 2^{\circ} \mathrm{C}$. Cry $1 \mathrm{Ab}$ content in the transgenic rice straw was quantified using a $B t$ Cry $1 \mathrm{Ab} / \mathrm{Ac}$ ELISA reagent box (American Enviro Logix Corporation). The final $B t$ rice straw feed contained $92.21 \mathrm{ng}$ of Cry1Abper gram of feed and the control feed had no detectable Cry $1 \mathrm{Ab}$ protein.

\section{Animals preparation}

Sixty mature and pathogen-free (SPF) (ICR) mice (30 males and 30 females) were purchased from the Hunan Slack Scene of Laboratory Animal Co., LTD. All animals were housed in groups ( 5 females or males in each group). Each group was housed in a stainless steel wire cage $\left(0.5 \mathrm{~m}^{3}\right.$ per cage) under $23 \pm$ $2{ }^{\circ} \mathrm{C}$ and $40-60 \%$ relative humidity at the Hunan SJA Laboratory Animal Co., Ltd. The test groups (15 females and 15 males) were fed with the $B t$ rice straw feed daily for $90 \mathrm{~d}$, and those in the control group ( 15 females and 15 males) were fed with control feed for $90 \mathrm{~d}$. Male mice are grouped separately from female mice. After the $90 \mathrm{~d}$ feeding trial, all mice were euthanized, and tissue samples were collected. ICR mice were weighted individually before and after dissection.

All procedures were carried out according to the approved guidelines of the Hunan Community Rules of Animal Care of Hunan Agricultural University Veterinary Services (China). All experimental protocols were approved by the Veterinary Inspection Department of Hunan Agricultural University (China). All surgery was performed under sodium pentobarbital anesthesia, and all efforts were made to minimize suffering.

\section{Blood and tissue sample preparation}

Individual blood samples were collected from eyeball veins and stored in heparin anticoagulation tubes for hemogram, blood biochemistry, and lymphocyte tests. Liver, brain, spleen, kidney, marrow, heart, ovary and testis were removed respectively for viscera index and enzyme activity assays. The blood and organ samples were immediately processed after dissection. Sperm quality and ovarian follicle growth and development were tested according to the method of Smith et al. (1995).

The apoptosis rate and calcium ion level in the blood lymphocytes were analyzed using the FCM FP1000 Flow Cytometry System (Beckman Corporation). The blood biochemistry indicators were tested using the OLYMPUS AU400 automatic biochemical analyzer. After dissection, organs, including liver, brain, spleen, kidney, marrow, heart, ovary, and testis, were individually weighed. Tissues $(0.2 \mathrm{~g}$ per sample) from each of these organs were collected and used to assay activities of various enzymes, including catalase (CAT), superoxide dismutase (SOD), peroxidase (POD), glutathione peroxidase (GSH-Px and acetylcholine esterase (AchE). Chinese Nanjing Jiancheng Bioengineering Institute manufactured all reagents.

\section{Data analysis}


The Significant difference $(p<0.05)$ was examined by the Wilcoxon signed-rank test using the SPSS 19.0.

\section{Results}

\section{Effects of Cry1 Ab rice straw on hematological indicators}

No adverse effects were found in a clinical appearance on animal behavior, including the diet intake, drinking and daily behavior (activity, posture, gait, external appearance) of ICR mice (data not shown). A total of 18 categories of hematological indicators were measured, and all the results are presented in Table 1. All data showed that the measured values were in the normal range. No significant difference was detected between the test and control groups. 
Table 1

Effects of transgenic $B t$ rice straw on the hematological indicators of mice

\begin{tabular}{|lllll|}
\hline Name & $\begin{array}{l}\text { Female control } \\
\text { group }\end{array}$ & $\begin{array}{l}\text { Female test } \\
\text { group }\end{array}$ & $\begin{array}{l}\text { Male control } \\
\text { group }\end{array}$ & Male test group \\
\hline WBC (109/l) & $17.15 \pm 2.88$ & $18.45 \pm 1.54$ & $19.77 \pm 1.83$ & $20.67 \pm 3.96$ \\
\hline $\begin{array}{l}\text { Lymph } \\
(109 / \mathrm{l})\end{array}$ & $10.95 \pm 2.72$ & $11.48 \pm 2.59$ & $12.20 \pm 2.53$ & $12.73 \pm 2.41$ \\
\hline Mon (109/I) & $1.35 \pm 0.46$ & $1.2 \pm 0.49$ & $1.28 \pm 0.45$ & $1.37 \pm 0.43$ \\
\hline Gran (109/l) & $6.33 \pm 2.73$ & $5.52 \pm 2.36$ & $6.68 \pm 1.84$ & $6.57 \pm 1.67$ \\
\hline Lymph (\%) & $60.73 \pm 7.51$ & $60.40 \pm 3.97$ & $63.45 \pm 9.76$ & $61.77 \pm 6.13$ \\
\hline Mon (\%) & $8.28 \pm 3.08$ & $7.63 \pm 1.25$ & $6.27 \pm 1.31$ & $6.98 \pm 0.72$ \\
\hline Gran (\%) & $31.28 \pm 4.68$ & $31.13 \pm 3.43$ & $32.08 \pm 8.04$ & $31.58 \pm 4.96$ \\
\hline RBC (1012/l) & $7.09 \pm 2.57$ & $7.15 \pm 1.88$ & $7.30 \pm 2.78$ & $7.91 \pm 0.86$ \\
\hline HGB (g/l) & $126.33 \pm 19.76$ & $122.00 \pm 36.91$ & $135.67 \pm 38.74$ & $136.50 \pm 18.16$ \\
\hline HCT (\%) & $43.95 \pm 10.46$ & $41.48 \pm 10.03$ & $45.90 \pm 8.18$ & $44.88 \pm 5.74$ \\
\hline MCV (fl) & $55.67 \pm 3.02$ & $56.38 \pm 2.22$ & $55.43 \pm 5.07$ & $56.70 \pm 2.23$ \\
\hline MCH (pg) & $16.73 \pm 1.45$ & $16.85 \pm 0.90$ & $16.95 \pm 1.22$ & $17.17 \pm 0.63$ \\
\hline MCHC (g/l) & $300.33 \pm 13.03$ & $299.33 \pm 8.50$ & $290.83 \pm 25.51$ & $303.50 \pm 8.17$ \\
\hline RDW (\%) & $13.25 \pm 0.59$ & $13.52 \pm 1.27$ & $13.22 \pm 0.69$ & $13.48 \pm 1.33$ \\
\hline PLT (109/l) & $2651.33 \pm 469.47$ & $2549.50 \pm 435.28$ & $2676.17 \pm 495.24$ & $2719.00 \pm 590.39$ \\
\hline MPV (fl) & $4.63 \pm 0.32$ & $4.62 \pm 0.15$ & $4.90 \pm 0.36$ & $4.98 \pm 0.20$ \\
\hline PDW & $15.53 \pm 0.52$ & $15.75 \pm 0.14$ & $15.97 \pm 0.75$ & $16.08 \pm 0.25$ \\
\hline PCT (\%) & $1.16 \pm 0.42$ & $1.15 \pm 0.30$ & $1.29 \pm 0.54$ & $1.36 \pm 0.49$ \\
\hline
\end{tabular}

Abbreviations: WBC: White blood cell; Lymph: lymphocyte; Mon: Monocyte; Gran: granulocyte; RBC: Red blood cell; HGB: Hemoglobin; HCT: Hematokrit; MCV: Mean corpuscular volume; MCH: Mean corpuscular hemoglobin; MCHC: Mean corpuscular hemoglobin concentration; RDW: Red cell distribution width; MPV: Mean platelet volume; PDW: Platelet distribution width; PCT: Thrombocytocrit.

Table 2 presents all measurements for nine biochemical blood factors. Three of them, including ALB, ALT, and ALT/AST, were slightly higher in the treatment group than in the control group, while LDH was lower in the treatment group than in the control group. Nevertheless, none of these differences were statistically significant. 
Table 2

Effects of transgenic Bt rice straw on the blood biochemistry indicators of mice

\begin{tabular}{|lllll|}
\hline Name & $\begin{array}{l}\text { Female control } \\
\text { group }\end{array}$ & $\begin{array}{l}\text { Female test } \\
\text { group }\end{array}$ & $\begin{array}{l}\text { Male control } \\
\text { group }\end{array}$ & Male test group \\
\hline TP $(\mathrm{g} / \mathrm{l})$ & $45.95 \pm 2.86$ & $44.80 \pm 2.28$ & $46.11 \pm 2.54$ & $47.25 \pm 2.08$ \\
\hline ALB $(\mathrm{g} / \mathrm{l})$ & $43.26 \pm 2.73$ & $46.43 \pm 2.61$ & $43.58 \pm 1.79$ & $45.65 \pm 1.64$ \\
\hline $\begin{array}{l}\text { UREA } \\
(\mathrm{mmol} / \mathrm{l})\end{array}$ & $5.68 \pm 0.18$ & $5.65 \pm 0.24$ & $5.52 \pm 0.24$ & $5.56 \pm 0.21$ \\
\hline TC $(\mathrm{mmol} / \mathrm{l})$ & $1.90 \pm 0.09$ & $1.93 \pm 0.12$ & $1.98 \pm 0.19$ & $1.97 \pm 0.08$ \\
\hline ALT $(\mathrm{u} / \mathrm{l})$ & $34.00 \pm 2.05$ & $35.26 \pm 1.42$ & $32.64 \pm 0.71$ & $33.46 \pm 2.05$ \\
\hline AST $(\mathrm{u} / \mathrm{l})$ & $90.28 \pm 1.30$ & $90.13 \pm 1.30$ & $89.77 \pm 1.31$ & $90.11 \pm 1.81$ \\
\hline LDH $(\mathrm{u} / \mathrm{l})$ & $218.88 \pm 2.38$ & $216.63 \pm 2.33$ & $218.22 \pm 1.48$ & $217.67 \pm 1.24$ \\
\hline ALP $(\mathrm{u} / \mathrm{l})$ & $106.65 \pm 1.77$ & $107.57 \pm 1.88$ & $108.77 \pm 1.66$ & $106.92 \pm 1.78$ \\
\hline ALT/AST & $0.38 \pm 0.03$ & $0.39 \pm 0.02$ & $0.36 \pm 0.00$ & $0.37 \pm 0.02$ \\
\hline Note: data are presented as mean group values $\pm \mathrm{SE}$. & & \\
\hline
\end{tabular}

Abbreviations: TP, total protein; ALB, albumin; TC, total cholesterol; ALT, alanine aminotransferase; AST, aspartate aminotransferase; LDH, lactic dehydrogenase; ALP, alkaline phosphatase.

\section{Effect of Cry1 Ab rice straw on the apoptosis rate of blood lymphocytes}

Although the number of apoptosis cells were $0.1 \%$ and $0.3 \%$ in the control group and test group of female respectively, while the number of apoptosis cells was $0.2 \%$ in the male control group and $0.3 \%$ in the male test group. Notably, the differences between the test and control had not attained the significant level statistically (Fig. 1).

\section{Effect of Cry1 $\mathrm{Ab}$ rice straw on the calcium ion content of blood lymphocytes}

As shown in Fig. 2, there were no significant differences in calcium ion content in the blood lymphocytes among groups during the whole study period, indicating no obvious effect on the blood lymphocytes.

\section{Effect of Cry1Ab rice straw on the enzyme activities of serum and organs}

There was no significant difference in CAT, GSH-Px, POD, SOD, and AchE activities in the serum between the test and control mice (Fig. 3). In addition, as shown in Fig. 4, there were no significant differences in organ weight between the test and control groups in the $90 \mathrm{~d}$ studies. This result indicated that Cry $1 \mathrm{Ab}$ 
protein did not affect organ development in mice. The activities of CAT, GSH-Px, POD, SOD and AchE in various organs of $90 \mathrm{~d}$ mice groups are shown in Fig. 5. For the female and male mice, the changes of these enzyme activities between the test group and the control group had no significant differences.

\section{Effect of Cry1Ab rice straw on the reproductive ability of the male and female mice}

As shown in Fig. 6 and Table 3, there were no significant differences in sperm grading, sperm count, sperm vitality, sperm motility rate, sperm abnormality rate, and sperm acrosome intact rate of male mice between the test group and control group. In addition, no significant differences in the number of follicles were detected between the test and control groups (Fig. 7). As shown in Fig. 8, under 40x magnification, all levels of follicle and corpus luteum were visible in the control and test groups. The number of follicles at all developmental stages is quite abundant; under 100x magnification, the structures of medulla and cortex and the follicular cavity were visible clearly, with clear texture; under $400 \times$ magnification, the morphology of the follicles was clear and complete, the contour rules and basement membrane were complete, the oocyte was surrounded by multi-layer granulosa cells around. No pathological findings during necropsy and no group-related histopathologic observations were found (Fig. 8).

Table 3

Effects of transgenic Bt rice straw on the quality of semen of mice

\begin{tabular}{|lll|}
\hline Items & Control group & Test group \\
\hline Sperm count $(108 / \mathrm{ml})$ & $6.92 \pm 0.25$ & $7.40 \pm 0.47$ \\
\hline Sperm vitality $(\%)$ & $60.7 \pm 3.75$ & $60.40 \pm 3.31$ \\
\hline Sperm motility rate $(\%)$ & $91.80 \pm 1.56$ & $92.9 \pm 1.20$ \\
\hline Sperm abnormality rate $(\%)$ & $5.30 \pm 2.71$ & $4.70 \pm 2.22$ \\
\hline Sperm acrosome intact rate $(\%)$ & $95.00 \pm 1.58$ & $95.60 \pm 1.29$ \\
\hline
\end{tabular}

\section{Discussion}


The basic safety assessment of genetically modified (GM) crops is based on the principle of "substantial equivalence" concept, but the "substantial equivalence" principle is a starting point rather than an endpoint (König et al., 2004; Muccilli et al., 2020). Giving the randomly inserted trait and the potential synergism with extrinsic factors of action mode of Bt protein, the expression level and recombination mode of Bt protein in different parts of the plant is not the same (Then, 2010). In any safety assessment of GM crops case, we all need novel and comprehensive methods, concepts and ideas to probe into the intended and/or unintended effects of GM technology and crops on target and/or non-target organisms, for the GM technology and crops need to be based on a scientific foundation. Thus, it has also become crucial to apply the case-by-case approach to assess the toxicity of GM plants, especially $B t$ rice, which plays an significant role in human health. Considering that the straw is the winter livestock feed for cattle in southern China, the unintended effects of Bt rice straw on mammalian especially on its reproductive system should also be valued despite much of the previous literature involving the safety assessment of $B t$ rice on mice,

When compared with the control mice, the dietary intake, drinking and daily behavior of ICR mice in the Cry1Ab rice straw fed group were normal and no toxicity or mortality was recorded during the 90-d experimental period. In a similar study, no adverse effects of Cry1Ab protein ( $B t$ rice) on animal behavior or weight increasing on Wistar rats were found (Schrøder et al., 2007). The physiological changes of the blood can directly reflect the health condition of animals. Apoptosis is an important indicator of animal toxicology and pathology (Zeng et al., 2015). Calcium ion has an extremely close relationship with apoptosis and participates in signal transduction regulation of apoptosis pathway (Clapham, 2007). This study demonstrated that no advert effects of Cry1 Ab protein exist on the hemogram (Table 1), blood biochemistry (Table 2), apoptosis rate and calcium ion concentration of the blood lymphocytes (Fig. 1-2), and CAT, GSH-Px, POD, SOD, AchE activities of serum (Fig. 3). The results showed that the Bt rice straw had no significant influence on the blood biochemistry of mice. These results are consistent with the previous research in a 90-d study of Sprague Dawley rats fed with transgenic T1C-1 rice expressing Cry $1 \mathrm{C}$ protein (Tang et al., 2012).

Organ index indicates the ratio of the organ weight to animal weight, which can directly reflect the status of animal disease or organ suffered from toxic effect. In the $90 \mathrm{~d} B t$ rice feeding study, we found that the organ index of ICR mice has no significant differences between the test and control groups (Fig. 4). These results are consistent with previous studies, which showed Cry1 Ab does not affect weight gain of Sprague-Dawley rat and Wistar rat (Schrøder et al., 2007; Wang et al., 2002). The antioxidants, including CAT, GSH-Px, POD and SOD that present widely in aerobic organisms can eliminate the free radicals (Jones, 2008; Sharma et al., 2018). In addition, AchE is closely related to neuronal development and regeneration (Fossati et al., 2015). In our study, we detected some enzyme activities related with reproduction in ICR mice organs in the test group, which showed that CAT, GSH-Px, POD, SOD, and AchE enzyme activities had no significant differences compared with those in the control group (Fig. 5). This phenomenon suggested that the growth and development of ICR mice organs didn't be influenced by taking in Bt rice straw powder for a long period (90 d). And Wang et al. (2013b) showed that there were no 
significant differences in rat organ weight and enzyme activities between the Cry $1 \mathrm{Ab}$ protein in test group and the control group in a $90 \mathrm{~d}$ study.

The sperm density is the most basic parameter in the reproductive safety assessment, and sperm motility is the main indicator of sperm quality. Sperm abnormalities have long been associated with male infertility and sterility, and sperm density and quality play a substantial role in fertilization and pregnancy outcomes (Chenoweth, 2005). As shown in Fig. 6 and Table 3, the sperm density was in the normal range and was not significantly different between the test and control groups. This finding also showed that Cry1 Ab protein exerted no detectable adverse effects on mice sperm vitality, sperm motility rate, sperm abnormalities and sperm acrosome intact rate, which are concordant with several previous studies (Ning et al., 2000; Wang et al., 2002). The safety assessment of Cry1C protein from genetically modified rice also showed that the Cry $1 \mathrm{C}$ protein had no significant effect on the incidence of sperm abnormality in mice (Cao et al., 2010). In addition, it was reported that there was no negative effect of $B t$ rice on testis of Sprague-Dawley rats (Wang et al., 2004). Another research also pointed out that Bt corn had neither longterm effects nor multi-generational dominant toxic effects on the development of germ cells and testes in the mice reproductive system, yet the Cry $1 \mathrm{Ab}$ have no association with the testes development of rats (Brake et al., 2004; Betz et al., 2000). The differences in ovarian organ index and follicle number at different levels were insignificant (Fig. 7). The granule cells were complete, and the corpus was visible in the test and control groups of female mice. The ovarian slices texture and structure were clear, and the morphology of follicles was no significant differences between the test and control groups (Fig. 8). The results showed that no adverse effects of $B t$ rice straw on the ovary and follicle of mice. The results were consistent with no significant difference in CAT, GSH-Px, POD, SOD and AchE in testes and ovary and corroborated each other. Thus, all results showed no adverse effects of $B t$ rice straw on the reproductive safety of female and male mice in the 90-d study. Our findings are supported by a study on three generations of mice fed with transgenic rice, which reported no potential adverse effect on the male reproductive axis, copulation index, fertility index, gestation length, live-birth rate and litter number (Zhou et al., 2012).

Cry proteins have high species-specific toxicity against certain insects. The mode of action in the target insect is through specific receptors in the gut, which is highly alkaline, with binding of the toxin resulting in pore-formation, osmotic imbalance, cell lysis and subsequent death of the insect (Palma et al., 2014). Due to species-specificity, the Cry proteins are regarded harmless or non-toxic to mammals, including humans. Hitherto, numerous data from toxicity studies have showed that no significant adverse effects of Cry proteins on body weight and clinical observations. The Bt insecticidal toxin-encoding gene has a long history of safe use in biotechnology (Mendelsohn et al., 2003). Animal feeding trials is an important assessment method for potential adverse effects of GM crops, and a $90 \mathrm{~d}$ rodent feeding study with GM food is suitable and valid (Poulsen et al., 2007). Nevertheless, animal's complex physiological structure and function sometimes could bring unforeseen difficulties in the experiment process and results (Zhou et al., 2012). We need to evaluate possible potential effects from transgenic crops through a large number of comprehensive analysis assessments. 


\section{Conclusion}

Rice is the main food crop of humanity, the further complex and long-term safety assessment study of $B t$ rice is required and necessary. Currently, there are few reports on the safety assessment of Bt rice straw. This study is focused on assessing potential unintended effects of Bt rice straw rather than determining qualitative and quantitative intrinsic toxicity of $B t$ rice constituents. Summing up the obtained results, no adverse effect was observed in ICR mice feeding $B t$ rice straw feed compared with the conventional nontransgenic rice straw feed in a $90 \mathrm{~d}$ study.

\section{Declarations}

\section{Statements and Declarations}

\section{Data Availability}

The data used to support the findings of this study are available from the corresponding author upon request.

\section{Consent to Publish}

All authors consent to publication of this manuscript.

\section{Plant Reproducibility}

These experiments have good reproducibility.

\section{Clinical Trials Registration}

Not applicable.

\section{Author Contribution}

Bo Lv \& Yun-e Tang, Data curation, Writing original draft. Chao-min Li \& Ou-lin Dai, Material preparation, Investigation. Yong Peng, Investigation. Zhi Wang \& Li-jun Chen, Conceptualization, Methodology..

\section{Conflict of Interest}

The authors declare that they have no known competing financial interests or personal relationships that could have appeared to influence the work reported in this paper.

\section{Funding}

This work was supported by the National Natural Science Foundation of China (Nos. 31472017, 31272339) and Project of Science and Technology Department of Hunan Province (No.2014FJ2003). 


\section{References}

1. Bel, Y., Ferré, J., Hernández-Martínez, P.. Bacillus thuringiensis toxins: functional characterization and mechanism of action. Toxins 12, 785 (2020).

2. Betz, F.S., Hammond, B.G., Fuchs, R.L.. Safety and advantages of Bacillus thuringiensis-protected plants to control insect pests. Regul Toxicol Pharmacol 32, 156-173 (2000).

3. Brake, D.G., Thaler, R., Evenson, D.P.. Evaluation of Bt (Bacillus thuringiensis) corn on mouse testicular development by dual parameter flow cytometry. J Agric Food Chem 52, 2097-2102 (2004).

4. Cao, S., et al. Safety assessment of Cry $1 \mathrm{C}$ protein from genetically modified rice according to the national standards of PR China for a new food resource. Regul Toxicol Pharmacol 58, 474481 (2010).

5. Carrière, Y., Showalter, A.M., Fabrick, J.A., Sollome, J., Ellers-Kirk, C., Tabashnik, B.E.. Cadherin gene expression and effects of $B t$ resistance on sperm transfer in pink bollworm. J Insect Physiol 55, 1058-1064 (2009).

6. Chenoweth, P.J.. Genetic sperm defects. Theriogenology 64, 457-468 (2005).

7. Clapham, D.E.. Calcium signaling. Cell 131, 1047-1058 (2007).

8. Fossati, S.M.,et al. Identification and expression of acetylcholinesterase in Octopus vulgaris arm development and regeneration: a conserved role for ACHE? Mol Neurobiol 52, $45-56$ (2015).

9. Hajimohammadi, B., et al. Safety assessment of genetically modified rice expressing Cry $1 \mathrm{Ab}$ protein in Sprague-Dawley rats. Sci Rep 11, 1126 (2021).

10. Jones, D.P.. Radical-free biology of oxidative stress. Am J Physiol Cell Physiol 295, C849-868 (2008).

11. König, A., et al. Assessment of the safety of foods derived from genetically modified (GM) crops. Food Chem Toxicol 42, 1047-1088 (2004).

12. Li, N., Xu, R., Duan, P., Li, Y.. Control of grain size in rice. Plant Reprod 31, 237-251 (2018).

13. Li, Z., et al. Responses of soil enzymatic activities to transgenic Bacillus thuringiensis (Bt) crops - A global meta-analysis. Sci Total Environ 651, 1830-1838, (2019).

14. Liu, Q., et al. Effects of transgenic Bt rice containing the Cry1 Ab protein on the gastrointestinal health of highly inbred wuzhishan pigs after two generations of feeding. J Agric Food Chem 66, 10575 10587 (2018).

15. Liu, Y., Li, N., Zhang, Z., Huang, C., Chen, X., Wang, F.. The central trend in crop yields under climate change in China: A systematic review. Sci Total Environ 704, 135355 (2020).

16. Liu, Z.,et al. Evaluating the non-rice host plant species of Sesamia inferens (Lepidoptera: Noctuidae) as natural refuges: resistance management of Bt rice. Environ Entomol 40, 749-754 (2011).

17. Melo, A.L., Soccol, V.T., Soccol, C.R.. Bacillus thuringiensis: mechanism of action, resistance, and new applications: a review. Crit Rev Biotechnol 36, 317-326 (2016).

18. Mendelsohn, M., Kough, J., Vaituzis, Z., Matthews, K.. Are Bt crops safe? Nat Biotechnol 21, 10031009 (2003). 
19. Muccilli, V., et al. Substantial equivalence of a transgenic lemon fruit showing postharvest fungal pathogens resistance. J Agric Food Chem 68, 3806-3816 (2020).

20. Ning, Z., Chen, M., Ma, J., Li, S.. Study on Mutagenicity of Cotton Seed Powder and Cotton Seed Oil of Transgenic CrylA(c)Cotton. J Agr biotechnol 8 (2000).

21. Palma, L., Muñoz, D., Berry, C., Murillo, J., Caballero, P.. Bacillus thuringiensis toxins: an overview of their biocidal activity. Toxins (Basel) 6, 3296-3325 (2014).

22. Poulsen, M., et al. Safety testing of GM-rice expressing PHA-E lectin using a new animal test design. Food Chem Toxicol 45, 364-377 (2007).

23. Raybould, A., Vlachos, D.. Non-target organism effects tests on Vip3A and their application to the ecological risk assessment for cultivation of MIR162 maize. Transgenic Res 20, 599-611 (2011).

24. Riaz Marral, M.W., Khan, M.B., Ahmad, F., Farooq, S., Hussain, M.. The influence of transgenic (Bt) and non-transgenic (non- $B t$ ) cotton mulches on weed dynamics, soil properties and productivity of different winter crops. Plos One 15, e0238716 (2020).

25. Savary, S., Willocquet, L., Pethybridge, S.J., Esker, P., McRoberts, N., Nelson, A.. The global burden of pathogens and pests on major food crops. Nat Ecol Evol 3, 430-439 (2019).

26. Schrøder, M., et al. A 90-day safety study of genetically modified rice expressing Cry $1 \mathrm{Ab}$ protein (Bacillus thuringiensis toxin) in Wistar rats. Food Chem Toxicol 45, 339-349 (2007).

27. Sharma, G.N., Gupta, G., Sharma, P.. A Comprehensive review of free radicals, antioxidants, and their relationship with human ailments. Crit Rev Eukaryot Gene Expr 28, 139-154 (2018).

28. Smith, S., Hosid, S., Scott, L.. Use of postseparation sperm parameters to determine the method of choice for sperm preparation for assisted reproductive technology. Fertil Steril 63, 591-597 (1995).

29. Song, H., et al. A 90-day subchronic feeding study of genetically modified rice expressing Cry $1 \mathrm{Ab}$ protein in Sprague-Dawley rats. Transgenic Res 24, 295-308 (2015).

30. Song, Y.Y., Liu, J.W., Li, L.K., Liu, M.Q., Chen, X.Y., Chen, F.J.. Evaluating the effects of transgenic Bt rice cultivation on soil stability. Environ Sci Pollut Res Int 27, 17412-17419 (2020).

31. Tang, X., et al. A 90-day dietary toxicity study of genetically modified rice T1C-1 expressing Cry $1 \mathrm{C}$ protein in Sprague Dawley rats. Plos One 7, e52507 (2012).

32. Then, C.. Risk assessment of toxins derived from Bacillus thuringiensis-synergism, efficacy, and selectivity. Environ Sci Pollut Res Int 17, 791-797 (2010).

33. Wang, E.H., Yu, Z., Hu, J., Jia, X.D., Xu, H.B.. A two-generation reproduction study with transgenic Bt rice TT51 in Wistar rats. Food Chem Toxicol 65, 312-320 (2014).

34. Wang, E.H., Yu, Z., Hu, J., Xu, H.B.. Effects of 90-day feeding of transgenic Bt rice TT51 on the reproductive system in male rats. Food Chem Toxicol 62, 390-396 (2013a).

35. Wang, Y., et al. Evaluation of the potential effect of transgenic rice expressing Cry1 Ab on the hematology and enzyme activity in organs of female Swiss rats. Plos One 8, e80424 (2013b).

36. Wang, Z.H., Wang, Y., Cui, H.R., Xia, Y.W., Altosaar, I.. Toxicological evaluation of transgenic rice flour with a synthetic cry 1 Ab gene from Bacillus thuringiensis. J Sci Food Agr (2002). 
37. Wang, Z.H., Wang, Y., Shu, Q.Y., Wu, D.X., Xia, Y.W.. Study on mutagenicity of transgenic rice flour with a synthetic Cry $1 \mathrm{Ab}$ gene from Bacillus thuringiensis. Scientia Agricultura Sinica (2004).

38. Xing, Y., et al. The impact of $B t$ maize expressing the Cry1 Ac protein on non-target arthropods.

Environ Sci Pollut Res Int 26, 5814-5819 (2019).

39. Ye, R., et al. Development of insect-resistant transgenic rice with Cry $1 C^{*}$-free endosperm. Pest Manag Sci 65, 1015-1020 (2009).

40. Zeng, W., Wang, X., Xu, P., Liu, G., Eden, H.S., Chen, X.. Molecular imaging of apoptosis: from micro to macro. Theranostics 5, 559-582 (2015).

41. Zheng, X., Zhu, L., He, G.. Genetic and molecular understanding of host rice resistance and Nilaparvata lugens adaptation. Curr Opin Insect Sci 45, 14-20 (2021).

42. Zhou, X.H.,et al. A three generation study with high-lysine transgenic rice in Sprague-Dawley rats. Food Chem Toxicol 50, 1902-1910 (2012).

\section{Figures}
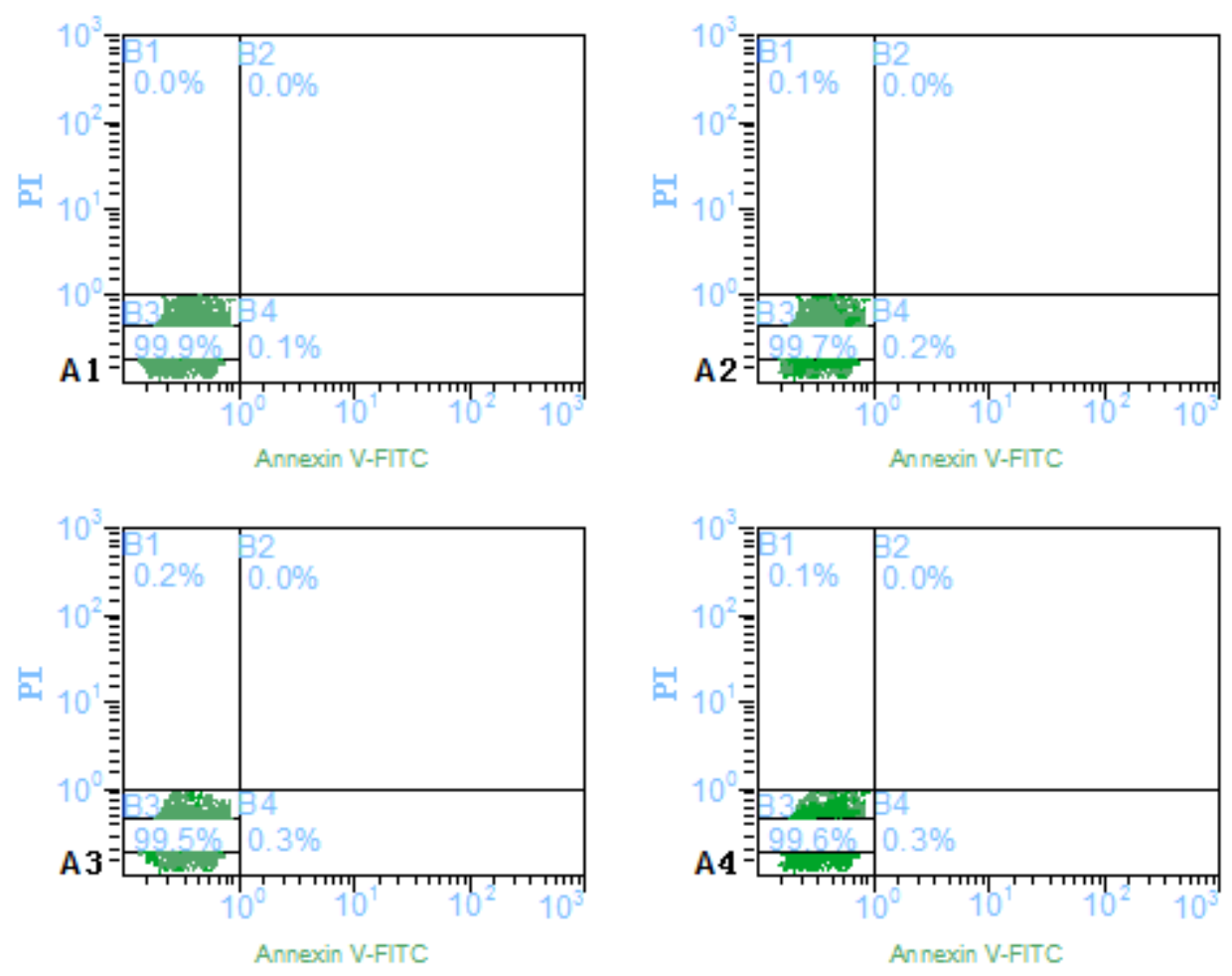

\section{Figure 1}

Effects of Bt rice straw on blood lymphocyte apoptosis of mice. A1: the female control group. A2: the male control group. A3: the female test group. A4: the male test group. Note: The $X$ coordinate means the percent of dyeing Annexin V cells. The Y coordinate means the percent of dyeing PI cells. The B1 
coordinate means the percent of necrosis cells and the late apoptosis cells. The B2 coordinate means the percent of dead cells of mechanical damage. The B3 coordinate means the percent of survived cells. The B4 coordinate means the percent of the early apoptosis cells. The total apoptosis rate was the sum of B2 and B4
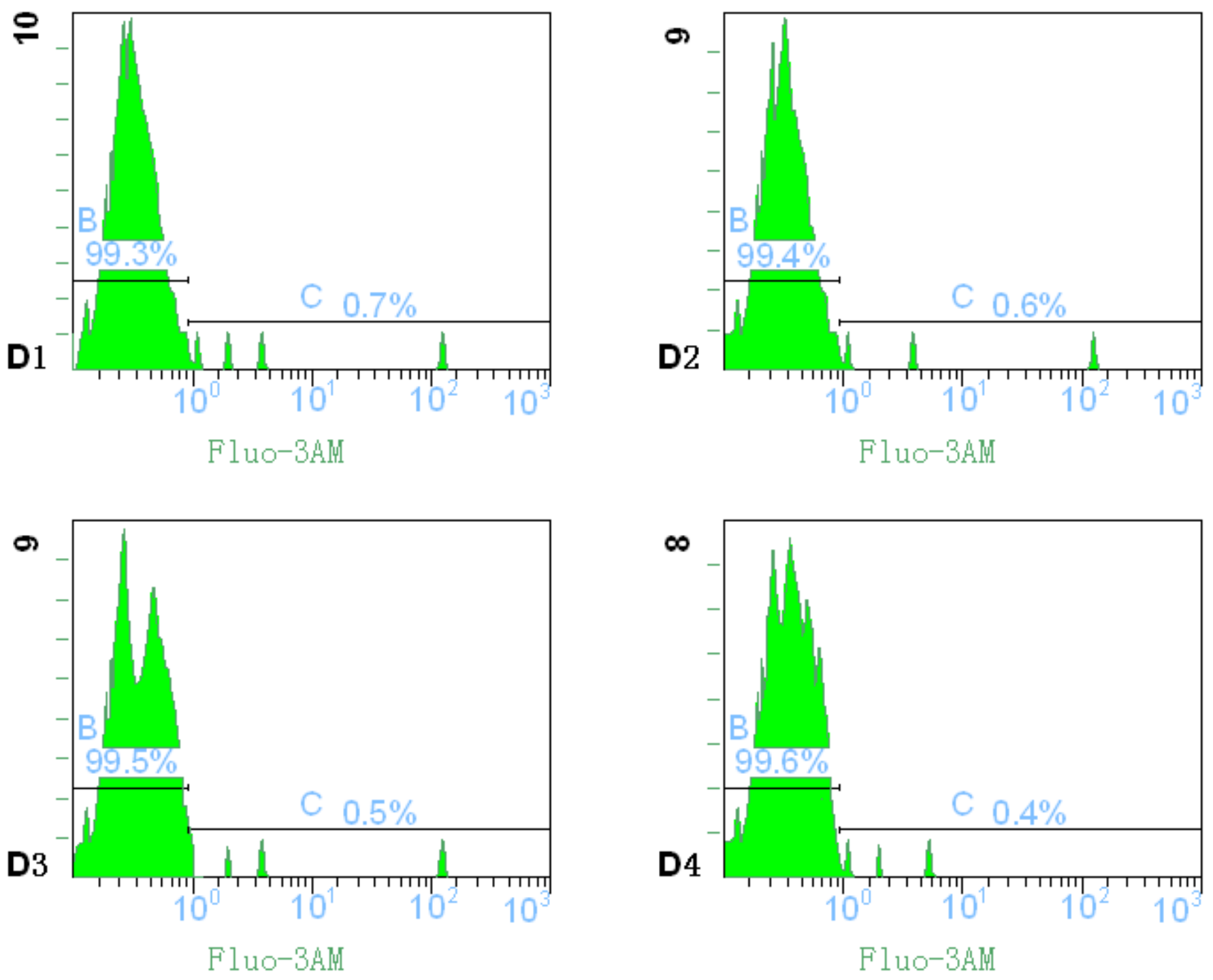

Figure 2

Effects of transgenic Bt rice straw on calcium currents of lymphocytes of mice blood. D1: the female control group. D2: the male control group. D3: the female test group. D4: the male test group 


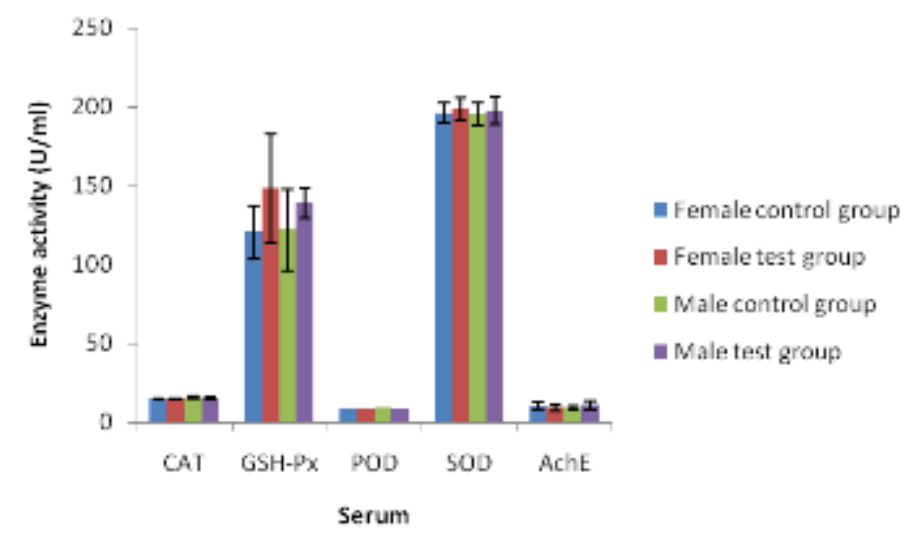

Figure 3

Effects of transgenic Bt rice straw on the enzyme activities of serum of mice

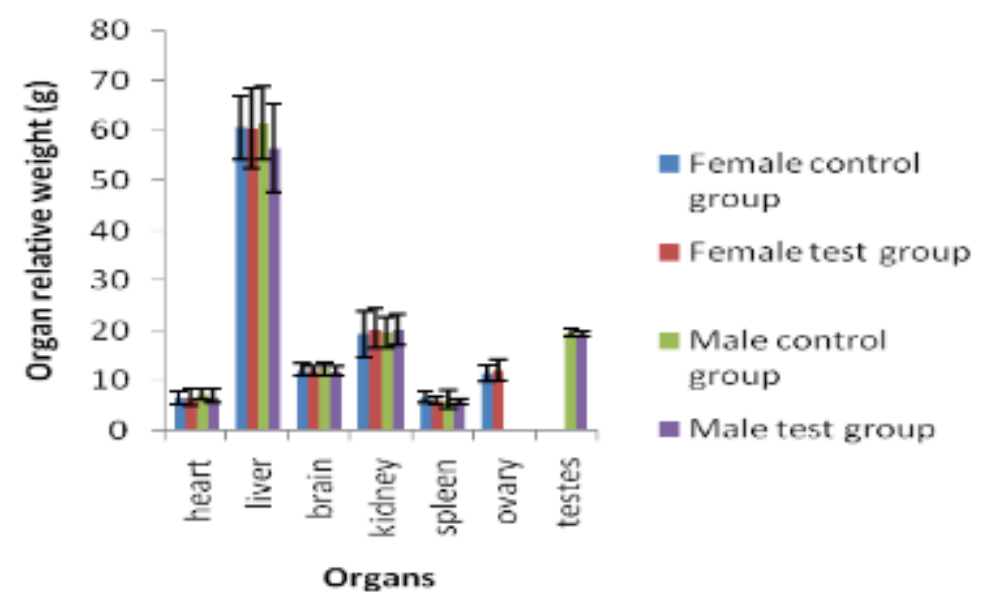

Figure 4

Effects of transgenic Bt rice straw on the organ index of mice 

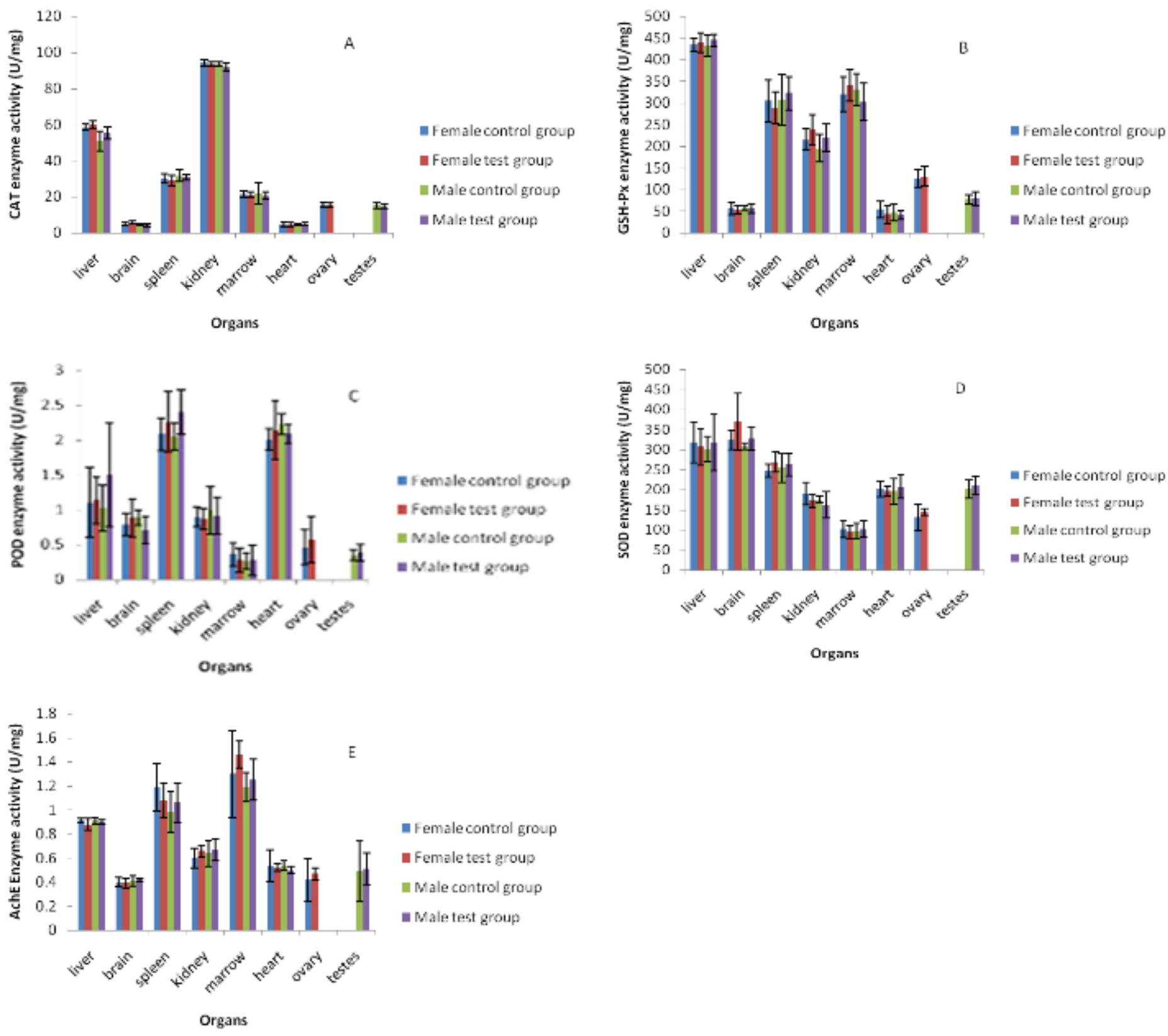

Figure 5

Effects of transgenic Bt rice straw on the enzyme activities of organs in mice. (A) catalase; (B) glutathione peroxidase; (C) peroxidase; (D) superoxide dismutase; (E) acetylcholinesterase

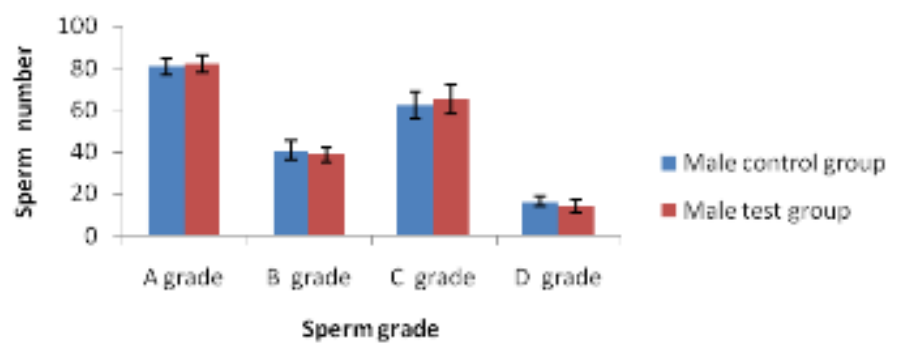

Figure 6 
The grading of sperm in the treated and control mice

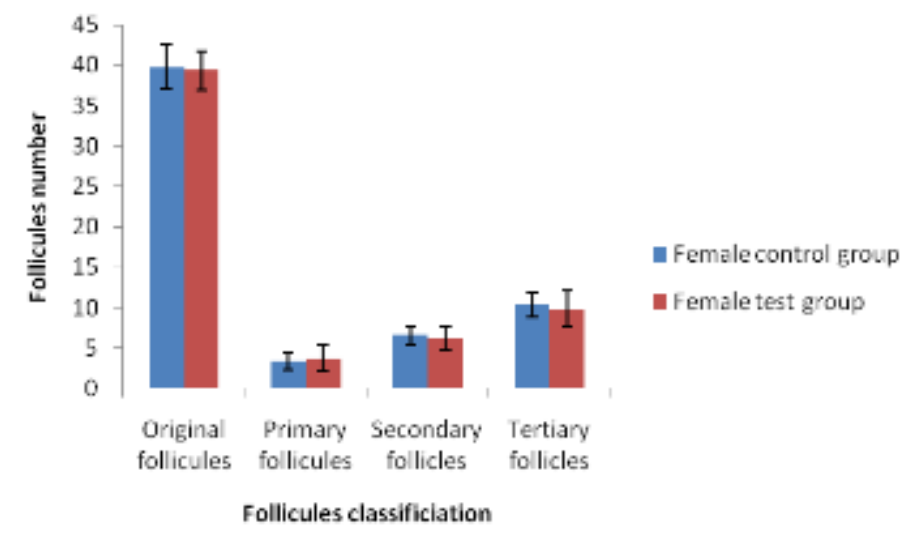

Figure 7

Effects of transgenic Bt rice straw on the number of follicles at all developmental levels in rat ovary

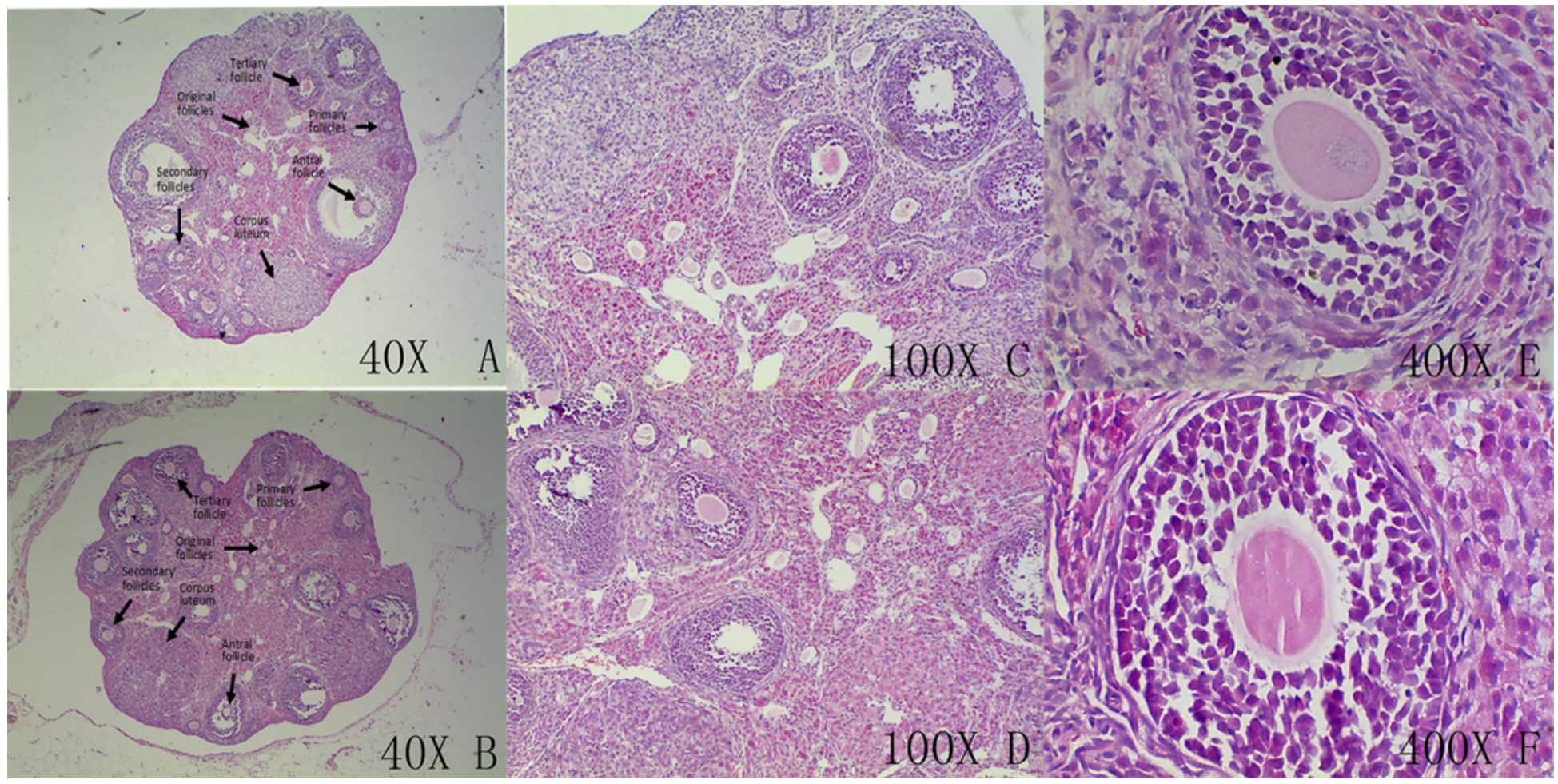

Figure 8

Pathological sections of follicles between the test and control mice Note: A, C, and E are sliced sections of control groups in $40 \times, 100 \times$ and $400 \times$ magnification respectively; $B, D$, and $F$ are sliced sections of test groups of $40 \times, 100 \times$ and $400 \times$ magnification, respectively. 